\title{
Interpersonal Meaning in RAs: Some Traces of Modality
}

\author{
Wawan Hendrawan ${ }^{1}$, Eva Tuckyta Sari Sujatna ${ }^{2}$, \\ Ekaning Krisnawati ${ }^{3}$, Nani Darmayanti ${ }^{4}$ \\ wawan18003@mail.unpad.ac.id ${ }^{1}$, eva.tuckyta@unpad.ac.id ${ }^{2}$, ekaning@unpad.ac.id ${ }^{3}$, \\ n.darmayanti@unpad.ac.id ${ }^{4}$ \\ Universitas Padjadjaran ${ }^{1,2,3,4}$
}

\begin{abstract}
Studies on interpersonal meaning have been well documented. However, few studies explored interpersonal meaning in the area of research articles. In responding to this, the present study tried to reveal interpersonal meaning in RAs' discussion sections. The data taken were from five reputable international journals categorized in the subject of language and linguistics indexed by Scopus with the SJR value above one. Having been analyzed by using the theory of modality from Halliday (1994), the data demonstrated that three types of modality values were identified such as high, middle, and low. In addition, there were some disparities among the results investigated. If sequenced, the low outnumbered the middle and the high values. This suggested that the authors had different assessments towards the topics written.
\end{abstract}

Keywords: discussion section, interpersonal meaning, modality, research article

\section{Introduction}

One of the most significant scholarly writings is research articles (henceforth: RAs) (Khansari, 2018), it has become one of the topics preferred to study for more than three decades (Ebrahimi, 2016). It is so important in an academic world that Montgomery (cited in Holtz, 2011) called it as "the grand master narrative of modernism". In writing RA, authors must act and position themselves in a very objective way (Martinez, 2001) due to the goal of creating RA is to convince the readers that the new knowledge has been claimed (Bazerman, 1988; Swales, 1990; Hyland, 1998; Dobakhti, 2014). RA poses certain characteristics that allow writers to give assumptions, predictions, or even doubt. These are realized by interpersonal meaning. In the context of the present research, this is understood as attitudinal, ethical and aesthetic evaluation of authors towards the topics presented (Eggins, 2004; Geng \& Wharton, 2019).

Comprehending interpersonal meaning is very essential for those who want to understand the authors' meaning (Abdollahzadeh, 2011). This will help them to locate the authors' position regarding the topics written (Nan \& Liu, 2013). By the same token, it will also show the way why they think so. In a research article, the author's stance apparently exists in the discussion section. This is not surprising due to the nature of it as a medium to discuss and interpret the results of the study (Dobakti, 2014). The results of the study are discussed and clarified by the authors based on their understanding of the frameworks or underpinning theories. Referring to this, discussion section becomes the key elements in RAs in that it presents the focal elements of the research as well as the medium to impress the readers (Dobakhti, 2014).

The studies related to the existence of authors' interpersonal meaning have been scrutinized based on the media where it remained, for instance presidential speech (Feng \& Liu, 2010), conclusion section (Abdollahzadeh, 2011), students' writing task (Wharton, 2012), course newsletters (Yuliana \& Imperiani, 2017), television advertisements (Hidayat, 
Abrizal, \& Alek, 2018), doctoral theses (Geng \& Wharton, 2019), and textbooks (Cheng, Lam \& Kong, 2019). Feng \& Liu (2010) studied the implementation of interpersonal meaning in Obama's presidential speech. Using functional grammar as the analytical tool focusing on several features of interpersonal meaning like mood, modal auxiliary, personal pronouns, and tense, the study found that Obama used all of the devices to achieve his political purpose. Therefore, the elements of interpersonal meaning employed delivered well the meaning intended.

Abdollahzadeh (2011) compared the works related to interpersonal metadiscourse written by Anglo-American and Iranian academic writers in the area of applied linguistics. The conclusion suggested that there were differences and similarities in term of rhetorical behavior regarding the use of interpersonal metadiscourse. Wharton (2012) analyzed interpersonal stance from the writing task jotted down by the first-year undergraduate statistics students. The results demonstrated that the students frequently deployed the stance by the use of modality. The most frequent modality feature was 'may' with eleven incidences followed by 'could' with frequency of five times. Geng and Wharton (2019) investigated how the writers of theses assessed their own and others' findings. The researchers found that the writers of those theses used three main patterns when discussing their own results and others' findings.

Yuliana and Imperiani (2017) probed the interpersonal meaning resided in the course newsletters bid by two institutions, Islamic and general. Six newsletters employed as the research data comprising of three newsletters taken from each institution. In term of modality, the study recognized that it was applied slightly in the course newsletters created by both institutions. Hidayat, Abrizal, and Alek (2018) figured out the interpersonal meaning of YOU C1000 on Indonesian television advertisements. They applied multimodal approach to explore the topic studied. The outcomes indicated that YOU C1000 advertisement enticed the audiences' attention successfully.

Cheng, Lam, and Kong (2019) inspected how effective workplace communication was instituted by the interpersonal ability. In realizing this, they analyzed some textbooks supporting the teaching of interpersonal meaning. The results indicated that the textbooks should address the deficiencies identified and present interpersonal language in the workplace very explicitly. The study also urged that teachers of ESP should not depend heavily on textbooks while teaching interpersonal language.

The above studies demonstrated how the interpersonal meaning realized in particular media. As seen, none of the aforementioned researches stated the investigation of interpersonal meaning in RAs' discussion sections. Motivated by this, the present study comes to fill the gap. It tries to examine how the interpersonal meaning realized in discussion section. Moreover, it specifically will underneath the existences of the modality values applied by the authors as the tools to discuss and interpret the results portrayed in their studies.

\section{Literature Review}

Modality is one of the tools to realize the interpersonal meaning (Aripin, 2018). It is the meaning that situates itself between yes and no (Halliday, 1994) and used as a way to assess the messages given (Eggins \& Slide, 1997). One of its identities is represented by auxiliary verbs (Adejare, 2014) or modal operators in the context of the present study. Since one of their functions is to serve the authors or speakers' judgments, the modal operators, thus, have scales showing their magnitude. These degrees will manifest the authorial stance towards the propositions made and further will affect the receptions of their propositions. Below explicated the categories of value of modal operators, as highlighted by the table 1.1. 
Table 1.1: The categories of value of modal operators

\begin{tabular}{cccc}
\hline & High & Median & Low \\
\cline { 2 - 4 } Modal & must & will & may \\
Operators & ought to & would & might \\
& need & shall & can \\
& has to & should & could \\
\hline
\end{tabular}

Source: Halliday (1994: 362)

Table 1.1 illustrates the categories of modal operators' rates. Their valuation is comprised of three layers that is high, median, and low. Moreover, the above modal operators are constituted into several specific words that represent their exact meaning. Their use will to some extent differentiate the intentions or judgments of the authors regarding the topics reported.

As one of the indicators to implement the conviction, modality also has its own interpretation when scrutinized. The values of modality used as a probability have their own level of degrees. Table 1.2 indicated how likely is something to occur while applying the high, median, and low value of modality. These rates display the possibility of the propositions made.

Table 1.2: Three values of modality probability

\begin{tabular}{cc}
\hline Value & Probability \\
\hline High & certain \\
Median & probable \\
Low & possible \\
\hline
\end{tabular}

Source: Halliday (1994: 358)

Table 1.2 elucidates the modality of probability values. Every value bears its own interpretation when utilized. The high modality degree shows the level of certainty when applied in a proposition. The median modality indicates that the proposition is probable, and the low modality suggested that the proposition is possible. Of course, these three degrees of probability will have an impact when applied in the context of communication verbally or nonverbally.

As the addition to the above explanation, the values of modality and their interpretive probability do not only show the authors' position towards the topic written but also reveal their interpersonal association with their readers or hearers (see Aripin, 2018). This relationship again is carved wholly by the authors or speakers themselves. When doing this, they must realize the meaning and effect of deploying the modal operators in their clauses or utterances. This is essential to avoid misconception of the proposition produced.

Contrary to the above explanation, the modal operators also bring their challenges as well. Their presence may be interpreted as conveying doubt (Abdollahzadeh, 2011), thus lowering the credibility of the authors. Although, initially it was deployed to exhibit 'civilized diffidence' (Abdollahzadeh, 2011) and lessen the "responsibility they might face in expressing the ideational material" (Williams cited in Abdollahzadeh, 2011: 290) still for some it can be viewed as ambivalence. This is also in line with other related studies recently conducted (Pranoto, 2018; Citraresmana, 2020).

\section{Method}

The data in this study were collected from five articles published in five reputable international journals such as Journal of Memory and Language (JML) (Robey, 2019), 
Language, Culture and Curriculum (LCC) (Bower, 2019), Brain and Language (BL) (Bice $\&$ Kroll, 2019), Language, Cognition and Neuroscience (LCN) (Kaiser, 2019), and Journal of Child Language (JCL) (Jones \& Brant, 2019). These journals are categorized into the subject of language and linguistics and included into the first quartile at Scimago Journal \& Country Rank (SJR). These data were utilized in the present study because they have SJR value above one. This signifies that they are really high impact journal and thus worth to be investigated as the research subject.

The data employed in this study were chosen purposefully (Creswell, 2003) and guided by the very tight election mean. Realizing this, the selection process of the data was based on the criteria that is they had to be written by those who had the affiliation with English speaking institutions and they must have been recently published articles. These steps were taken to make sure that the data contained the language practiced by native speakers and they are still up to date hence the results gained will be comprehensive.

Due to a research article consists of several structures or generic structures, the analytical process of the data was not done to all of the components residing in it. Following this, it was winnowed by the focus of the study. Again, the study concentrated to investigate the modality or modal operators in the discussion section. To this end, only the data taken from discussion section were analyzed. Discussion section was chosen as the locus because it contains authors' interpretation or in Fryer term's (Bazerman, 1988) it is due to its "interpretative nature".

Since this study centralized in the modality, hence only modality analyzed and interpreted. When analyzing the modality, the researchers did not only rely on the meaning of the modal operators but they also considered the contexts surrounded the modal operators exploited. Therefore, it also involved the understanding of their degrees that further classified as low, middle, and high (Halliday, 1994).

The approach used was qualitative inquiry operationalized by descriptive technique with simple calculation in depicting, analyzing, and interpreting the data (Creswell, 2003). While analyzing and interpreting the data, the framework about modal operators adopted from Halliday (1994) was implemented. As for the procedures of the data analyses, the researchers performed several steps such as first the articles that had already been chosen were collected. Second, the researchers read the articles by concentrating to the discussion sections. Third, the researchers pored over the clauses written in the discussion sections and then selected the clauses containing modal operators. Fourth, having collected, they were compartmentalized according to their categories and values. The last, after classified, they were analyzed and interpreted based on the framework applied.

\section{Results}

This study investigated the existence of modality and its degree in relations to the authors' interpersonal meaning. Therefore, the results presented were in accordance with it. After the data were analyzed, the outcomes demonstrated that three types of modality were found. These were high, median, and low modal operators. These results based on the investigation of the data taken from JML, LCC, BL, LCN, and JCL. For clarity, see table 1.2 .

Table 1.3: The overall sums of modal operator occurrences

\begin{tabular}{ccccccccc}
\hline Name of & & & & \multicolumn{2}{c}{ Degree \& } & Frequency & & \\
\cline { 5 - 7 } Journals & High & Incidence & Median & Incidence & Low & Incidence & Total & Total \% \\
\hline JML & - & - & Should & 6 & Could & 1 & 7 & $12.96 \%$ \\
\hline LCC & - & - & Would & 5 & Can & 2 & 20 & $37.03 \%$ \\
& & & Will & 2 & May & 9 & & \\
\hline
\end{tabular}




\begin{tabular}{|c|c|c|c|c|c|c|c|c|}
\hline & & & & & $\begin{array}{l}\text { Could } \\
\text { Might }\end{array}$ & $\begin{array}{l}1 \\
1 \\
\end{array}$ & & \\
\hline $\mathrm{BL}$ & - & - & $\begin{array}{c}\text { Should } \\
\text { Would } \\
\text { Will }\end{array}$ & $\begin{array}{l}1 \\
6 \\
1\end{array}$ & $\begin{array}{c}\text { May } \\
\text { Could } \\
\text { Might } \\
\text { Can } \\
\end{array}$ & $\begin{array}{l}8 \\
2 \\
1 \\
1 \\
\end{array}$ & 20 & $37.03 \%$ \\
\hline $\mathrm{LCN}$ & Is to & 2 & - & - & Can & 1 & 3 & $5.55 \%$ \\
\hline JCL & $\begin{array}{l}\text { Is to } \\
\text { Must }\end{array}$ & $\begin{array}{l}1 \\
1 \\
\end{array}$ & - & - & May & 2 & 4 & $7.43 \%$ \\
\hline Overall & & 4 & & 21 & & 29 & 54 & $100 \%$ \\
\hline Total \% & & $7.40 \%$ & & $38.88 \%$ & & $53.72 \%$ & & \\
\hline
\end{tabular}

Table 1.3 summed up the overall numbers of modal operators found in the data. The total numbers were 54. This statistic derived from the five journals scrutinized. The first was JML numbering as many as seven modal operators, LCC and BL each applied twenty modal operators, LCN three modal operators, and JCL four modal operators. These modal operators further constituted of several categories such as high, median, and low. The overall numbers of high modal operators identified was four and its overall percentage was $7.40 \%$. This originated from two journals such as LCN and JCL. As for LCN, the high modal operators spotted were two signified by 'is to'. Whereas for JCL, there were two high modal operators recognized and they were represented by 'is to' and 'must' successively.

Regarding the median value, the overall modal operators pinpointed were twenty one and its overall percentage was $38.88 \%$. These results emerged from three journals that is JML, LCC, and BL. In JML, it was found six modal operators signified by the word 'should', whereas in LCC diagnosed seven modal operators symbolized by 'would' and 'will' five and two occurrences consecutively. BL, on the other hand, contained six modal operators signaled by 'should', 'would', and 'will' each numbered one, six, and one sequentially.

The last was the low value, the overall modal operators found related to it was twenty nine and its overall percentage was $53.70 \%$. This result emanated from all of the data analyzed such as JML, LCC, BL, LCN, and JCL. As for JML, it was found only one represented by the word 'could'; in LCC there were 13 modal operators identified signified by the words 'can', 'may', 'could', and 'might' as many as two, nine, one, and one in succession. For BL, there were 12 modal operators comprising of several words like 'may', 'could', 'might', and 'can' as many as eight, two, one, and one successively. As for LCN, it was identified one modal operators represented by the word 'can' and in JCL it was seen two modal operators expressed by the word 'may'.

In addition, all of the aforementioned modal operators were scrutinized from all of the clauses analyzed in the discussion sections. The clauses analyzed all in the form of declarative clauses, none of them composed of other forms like interrogative or exclamative clauses. The use of declarative clauses well informed the meaning intended by the authors.

\section{Discussion}

\section{High Modal Operators}

As indicated by the results above, the frequency of the high modal operators is fewer compared to the middle and low modal operators. It only occurred in two journals such as LCN and JCL. Interestingly, from both journals, none of the median modal operators are found. Likewise, the low modal operators identified also lesser compared to the others that do not employ the high modal operators. These findings raise question why it happened. The probable answer would be that the authors of them want to make sure that the things jotted down are certain. By this, they intend to impose what they believe to their readers and thus 
they are full of conviction when conveying their predictions. This can be seen from one of the excerpts taken from JCL (Jones \& Brant, 2019: 9) as elucidated below.

"What the current study shows is that any explanatory model of early vocabulary development, particularly of early word production, must account for word sound features." (JCL, 46(5): 9)

If we closely look to the above statement, it tells about the authors' study related to the early vocabulary development that affects the features of word sound. 'Must' as described in the excerpt above has a meaning of 'certainty'. It is considered as the high value modal operators based on Halliday's (1994) taxonomy. By applying the word 'must', the authors aim to assert that their analysis is very likely to happen. By so doing, they expect that the readers will not doubt nor distrust their research findings. Therefore, the readers can fully accept the notion presented.

The use of the word 'must' in the above excerpt could also be understood as a way to show that the authors desire to distance the relationship with the readers by making the statement more convincing. In addition, it seems that the authors do not give any 'opportunity' to the readers in conflicting the claim made. Therefore, it is very unlikely that the readers could 'participate' in that notion.

The authors' 'move' by applying the word 'must' is completely fine since the topic articulated is related to a research that needs to be expressed competently. Furthermore, their research involves complex statistical tabulation that requires a tool to convey it clearly without any uncertainty in that the end result of it must be the same in all circumstances. That is why the word 'must', in the above excerpt, could to some extent represent the meaning intended due to the nature of research and findings resulted.

\section{Median Modal Operators}

With respect to the median modal operators, the results suggested that their number is not as many as the low modal operators. Yet, their presents outweigh the high modal operators. To the surprise of the researchers, this occurred in three journals viz. JML, LCC, and BL. The rest do not apply the middle modal operators. Again, as argued in the discussion of high modal operators, it is due perhaps to the methodology utilized and the nature of the topics presented in those studies. These, thus, prevent the median modal operators to take place.

In the context of the present research, it can be assumed that the median modal operators are implemented to carry the meaning of 'probability' (Halliday, 1994). Its place is between the high and the low. Thus, it brings the middle interpretation amid the certainty and possibility. To add more, their being reveals that the authors aim to take a middle distance with their readers. In this case, the authors do not intend to highly assert nor to give low authority to the readers through their works. This notion can be observed from one of the excerpts taken from JML (Robey, 2019: 13) exemplifying the middle modal operator.

"All results regarding this measure, however, should be taken cautiously." (JML, 108: 13)

'Should' in the aforementioned excerpt has a meaning of advice. The use of it signifies that the author tries to inform the readers that the results presented in the study described is advised to follow. The degree of the impact of the word 'should', in this context, is not too binding for the readers. As the consequence, the readers are given the chances to not follow the suggestion if it does not match their needs or believes. 


\section{Low Modal Operators}

As contrasted with the high and middle, the existence of low modal operators are greater in term of number. Compared with the high, the disparities were quite enormous, almost half of those utilized as the high modal operators. At the same time, there was also a correlation between the journals whose contributors do not apply the high modal operators, these journals would have greater sums of low modal operators. In other words, if a high modal operator is not deployed, then the low modal operator will be more prevailed. This is an important finding in the context of the present research.

The application of low modal operators in the data suggested that the statements made have low certainty (Halliday, 1994). Even so, in term of interpersonal meaning, it allows the readers a room to argue or doubt regarding the proposition produced. By applying this, the authors propose to eradicate the distance between the audiences and them. Of course, this measure is very good because the purpose of making a research article is not only for science per se but also has the aims to persuade readers (Geng \& Wharton, 2019). One of the examples realizing this is found in the data portrayed in the below excerpt (LCC, Bower, 2019: 14).

"This may relate to the nation-specific CLIL profile of England-in these schools, learners of all abilities enter their language national exams at least one year earlier than their peers and revert to English for the curriculum subject." (LCC: 14)

The meaning of the word 'may' in this context is possibility (Halliday, 1994). By using it, the author tries to propose an idea that has a somewhat lesser degree of probability. Her meaning may be interpreted as a 'move' offering something causing a connection to the profile of national-specific CLIL enduring in England. By narrating like this, she does not project herself as a more intelligible person, rather than giving the readers to argue or to have other perspectives. This way, further, reflects her humble trait when presenting her opinions. Even her thought realized in a very 'simple' manner. Yet, prudence is noticed in the rest of her clause indicating the reason supporting her claim.

The above excerpt is only one of the examples, taken from LCC, manifesting the low modal operators. Still there are two more journals having the same circumstances. In those two journals, the high certainty avoidance was noticeable especially from JML and BL. In these journals the contributors do not implement high modal operators that is why the low modal operators are prevailing. From this, it can be inferred that most of the writers in JML, LCC, and BL are playing safely in the same time they are implementing politeness scenario (Cheng \& Unsworth, 2016).

All in all, the above discrepancies of value signify that the authors have different intentions in communicating their thought and further the divergences also state that the claims of the authors corresponding to the certainty or uncertainty are fluctuating (cf. Aripin, 2018). Writing a research article particularly the discussion section needs the involvement of 'humanity touch' since it involves not only objective standing points as once believed but also it requires the ability to persuade viewers to whom the works addressed (Geng \& Wharton, 2019).

\section{Conclusion}

There are some conclusions drawn from the overall results. First, all of the articles in the journals were analyzed by utilizing modal operators. Even so, there are divergences in terms of frequencies of modal operators employed. Second, the low modal operators overruled the others. It implies that all of the authors whose works being investigated to 
some extent wanted to avoid high certainty or show their humility towards the topics written. Third, there was a significant correlation between the implementation of low and high modal operators in the data evaluated. If the low modal operators more deployed in the manuscript, then the existence of high modal operators would be fewer or even did not exist. Fourth, the application of high modal operators was in a very limited mode. It suggested to some degree that the authors were not being 'certain' to the ideas offered and evaded to be 'authoritative' to their readers. Fifth, all of the modal operators figured out embodied in the declarative clauses. It supported the previous research findings (Aripin, 2018) evincing that a declarative clause functioning to manifest information and not to order nor question. Finally, the results of the present study overturned the claim that interpersonal markers were less practiced (Crismore, Markannen, \& Steffensen, 1993).

Since this study is close to the topic of English for specific purpose in that it discusses a topic related to how the authors' stance reflected in their RAs, thus it has direct consequence to the teaching of it. Following this, it is described some relevance to its pedagogical purposes. First, lecturers or teachers can inform the students that if they want to know the author' point of standing they can learn the topic of interpersonal meaning. Second, lecturers or teachers more specifically can use the materials in the form of RAs if the students want to know the authors' attitudes in RAs. This will have the significance for the students; first they will learn about generic structures of RAs and second, they will learn about the authors' stance in RAs. When learning about the authors' stance in RAs, the students can identify it by recognizing the types of modality used in the RAs, particularly in the section under the heading of discussion. By doing this, the students will gain the knowledge of modality and the lexicogrammatical elements analyzed in the clauses containing the modal operators. The last, by mastering the concept of authorial stance, it is expected that the students would not too rush in claiming or supposing something in their written works. This will, finally, lead to develop them as a potential writer that possessed a humble and wise characters.

\section{References}

Abdollahzadeh, E. 2011. Poring over the findings: Interpersonal authorial engagement in applied linguistics papers. Journal of Pragmatics, 43, 288-297.

Adejare, R.A. 2014. The manifestation of mood and modality in texts. English Linguistics Research, 3(1), 18-27.

Aripin, A. 2018. How non-native writers realize their interpersonal meaning? Lingua Cultura, 12(2), 155-161.

Bazerman, C. 1988. Shaping Written Knowledge: The Genre and Activity of the Experimental Article in Science. Wisconsin: The University of Wisconsin Press.

Bice, K. \& Kroll, J.F. 2019. English only? Monolinguals in linguistically diverse contexts have an edge in language learning. Brain and Language, 196, 1-12.

Bower, K. 2019. School leaders' perspectives on content and language integrated learning in England. Language, Culture and Curriculum.

Citraresmana, Elvi. 2020. Conceptual meaning of secretary in academic students of secretary's cognition in Bandung. Teknosastik: Jurna Bahasa dan Sastra, 18(1), 4249. 
Cheng, W., Lam, P.W.Y. \& Kong, K.C.C. 2019. Learning English through workplace communication: Linguistic devices for interpersonal meaning in textbooks in Hong Kong. English for Specific Purposes, 55, 28-39.

Cheng, F.W. \& Unsworth, L. 2016. Stance-taking as negotiating academic conflict in applied linguistics research article discussion sections. Journal of English for Academic Purposes, 24, 43-57.

Creswell, J.W. 2003. Research Design: Qualitative, Quantitative, and Mixed Methods Approaches, $2^{\text {nd }}$ Edition. California: Sage Publication.

Crismore, A., Markannen, R., Steffensen, M.S. 1993. Metadiscourse in persuasive writing: A study of texts written by American and Finnish University students. Written Communication, 10(1), 39-71.

Dobakti, L. 2014. The use of hedges in the discussion section of qualitative and quantitative research articles. The Asian ESP Journal, 10(2), 163-190.

Ebrahimi, S.F. 2016. Across disciplinary study of marked theme in method sections. The Journal of Teaching English for Specific and Academic Purposes, 4(3), 689-699.

Eggins, S. \& Slade, D. 1997. Analyzing casual conversation. London: Cassell.

Feng, H. \& Liu, Y. 2010. Analysis of interpersonal meaning in public speeches-a case study of Obama's speech. Journal of Language Teaching and Research, 1(6), 825829.

Geng, Y. \& Wharton, S. 2019. How do thesis writers evaluate their own and others' findings? An appraisal analysis and a pedagogical intervention. English for Specific Purposes, 56, 3-17.

Halliday, M. A. K. 1994. An Introduction to Functional Grammar, $2^{\text {nd }}$ Edition. Great Britain: Edward Arnold.

Hidayat, D. N., Abrizal. Alek. 2018. A multimodal discourse analysis of the interpersonal meaning of a television advertisement in Indonesia. IJEE: Indonesian Journal of English Education, 5(2), 119-126.

Holtz, M. 2011. Lexico-grammatical properties of abstracts and research articles: A corpusbased study of scientific discourse from multiple disciplines. Accessed from http://tuprints.ulb.tu-darmstadt.de/2638.

Hyland, K. 1998. Hedging in Scientific Research Articles. Amsterdam: Benjamins.

Jones, S.D. \& Brant, S. 2019. Do children really acquire dense neighbourhoods? Journal of Child Language, 46(5), 1-14.

Kaiser, E. 2019. Linguistic consequences of event segmentation in visual narratives: Implications for prominence. Language, Cognition and Neuroscience, 34, 1-7.

Khansari, D. 2018. Comparison of rhetorical moves in the method sections of two disciplines. The Asian ESP Journal, 14(7.1), 163-192.

Martinez, I. A. 2001. Impersonality in the research article as revealed by analysis of the transitivity structure. English for Specific Purposes, 20, 227-247.

Nan, Y. \& Liu, L. 2013. Investigating the interpersonal and textual meaning of Steve Jobs' Stanford speech in terms of Hyland's metadiscourse theory. International Journal of Language and Linguistics, 1(4), 90-96. 
Pranoto, Budi Eko \& Afrilita, Lidia K. 2018. The organization of words in mental lexicon: evidence from word association test. Teknosastik: Jurna Bahasa dan Sastra, 16(1), 26-33.

Robey, A. 2019. The benefits of testing: Individual differences based on student factors. Journal of Memory and Language, 108, 1-17.

Swales, J. M. 1990. Genre Analysis: English in Academic and Research Settings. Cambridge: Cambridge University Press.

Wharton, S. 2012. Epistemological and interpersonal stance in a data description task: Findings from a discipline-specific learner corpus. English for Specific Purposes, 31, 261-270.

Yuliana, D. \& Imperiani, E.D.A. 2017. The realization of interpersonal meaning in course newsletters: A systemic functional linguistic perspective. Indonesian Journal of Applied Linguistics, 7(1), 181-188. 